\title{
Entrapment of xylanase within a PEG net-cloth grafted on polypropylene nonwoven fabrics with exceptional operational stability and its application for hydrolysis of corncob hemicelluloses
}

Lihua Zhang, ${ }^{a, b}$ Yuhong Ma, ${ }^{c}$ Changwen Zhao, ${ }^{a, b, *}$ Bin He, ${ }^{a, b}$ Xing Zhu, ${ }^{a, b}$ Wantai Yang $^{a, b, *}$

${ }^{\text {a }}$ State Key Laboratory of Chemical Resource Engineering, Beijing University of Chemical Technology, Beijing 100029, China

${ }^{b}$ Beijing Laboratory of Biomedical Materials, Beijing University of Chemical Technology, Beijing 100029, China

${ }^{\mathrm{c}}$ Key Laboratory of Carbon Fiber and Functional Polymers, Ministry of Education, Beijing University of Chemical Technology, Beijing 100029, China

*Corresponding author. E-mail: yangwt@mail.buct.edu.cn zhaocw@mail.buct.edu.cn 


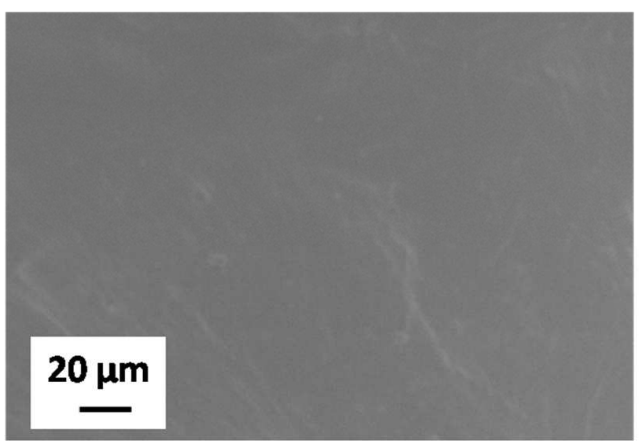

Figure S1. SEM image of the $\mathrm{PP}_{\mathrm{NWF}}-\mathrm{PEGDA}$ after being immersed for 6 months.

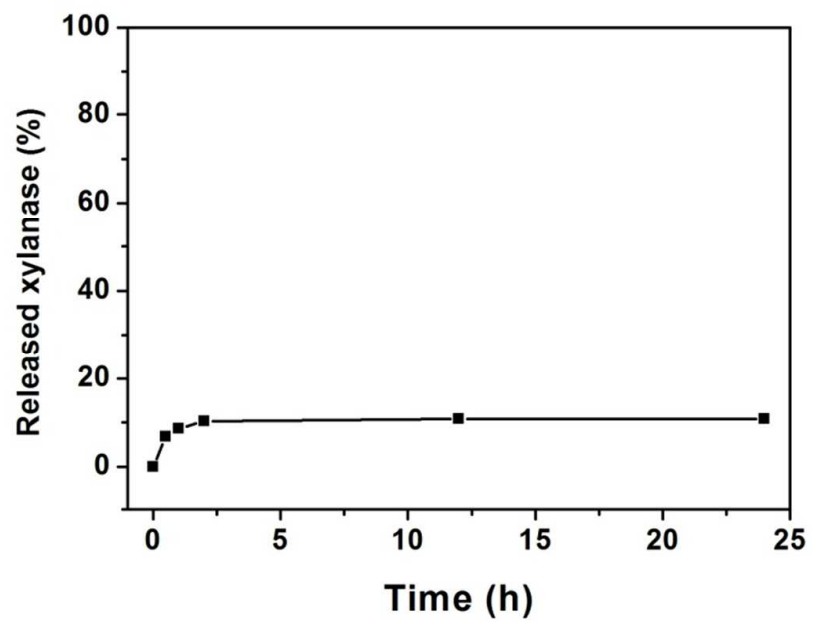

Figure S2. Release behavior of the loosely entrapped xylanase after the in situ immobilization. The conditions for this $\mathrm{PP}_{\mathrm{NWF}}-\mathrm{xylanase}$ membrane: the feed volume $=2 \mathrm{~mL}$, PEGDA: $($ xylanase solution $)=1: 1(\mathrm{v} / \mathrm{v})$, xylanase solution concentration $=$ $9.28 \mathrm{mg} / \mathrm{mL}$, irradiation time $=0.5 \mathrm{~h}$. 


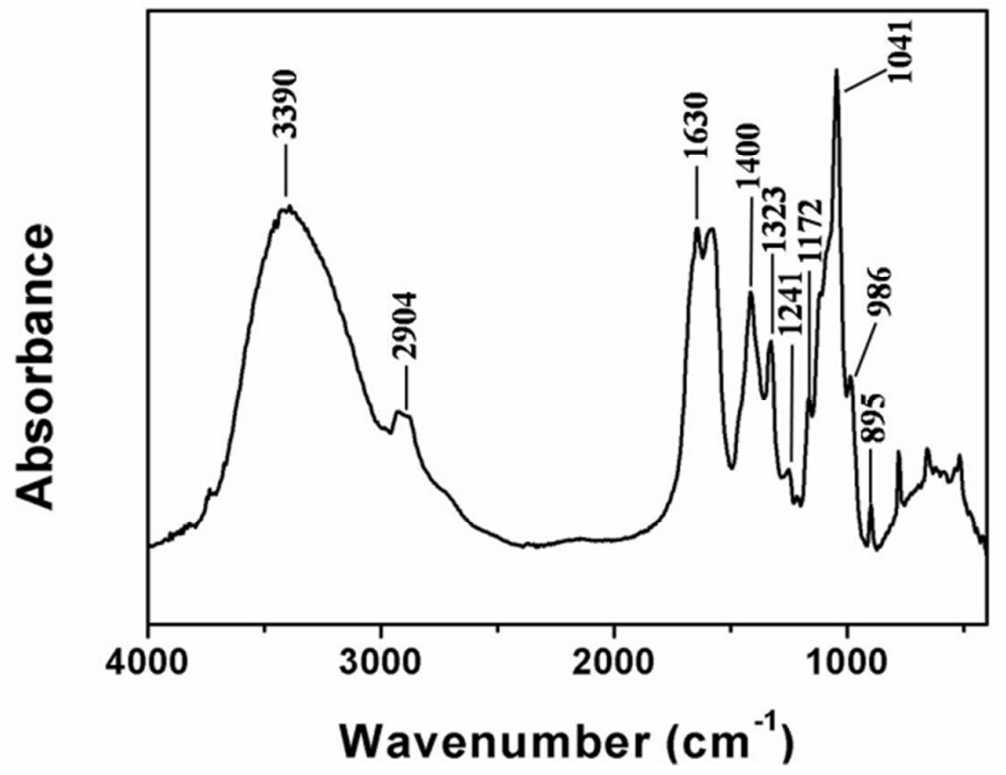

Figure S3. FTIR spectrum of the extracted hemicelluloses from corncob. 

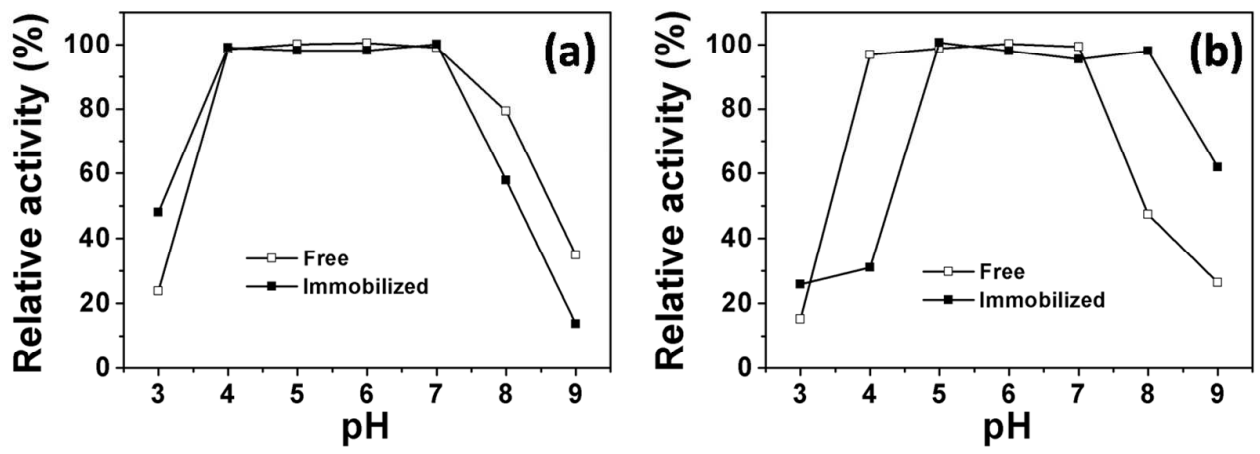

Figure S4. (a) Effect of $\mathrm{pH}$ on activity of immobilized and free $\beta$-xylosidases. (b) $\mathrm{pH}$ stability curves of immobilized and free $\beta$-xylosidases.
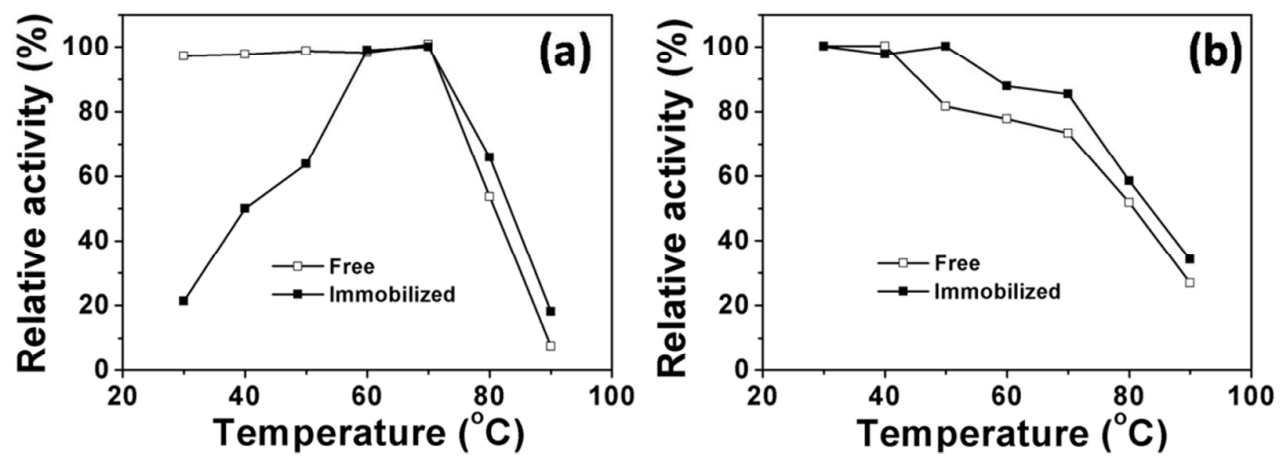

Figure S5. (a) Effect of temperature on activity of immobilized and free $\beta$-xylosidases.

(b) Thermal stability curves of immobilized and free $\beta$-xylosidases. 